\title{
The human, societal, and scientific legacy of cholera
}

\author{
William B. Greenough III \\ Division of Geriatric Medicine, Department of Medicine, and Division of International \\ Health, Bloomberg School of Public Health, Johns Hopkins University, Baltimore, \\ Maryland, USA
}

The recent history of research on cholera illustrates the importance of establishing research and care facilities equipped with advanced technologies at locations where specific health problems exist. It is in such settings, where scientific research is often considered difficult due to poverty and the lack of essential infrastructure, that investigators from many countries are able to make important advances. On this, the 25 th anniversary of the founding of the International Centre for Diarrhoeal Disease Research, Bangladesh (ICDDR,B), this article seeks to recount the Centre's demonstration of how high-quality research on important global health issues, including cholera, can be accomplished in conditions that may be considered by many as unsuitable for scientific research.

\section{J. Clin. Invest. 113:334-339 (2004). doi:10.1172/JCI200420982.}

Cholera kills by swiftly draining away body fluids. It is an ancient scourge, yet research on this disease has yielded insights into fundamental biological processes and established effective treatment that is within reach of everyone, even those who live in resourcepoor, underserved areas of the planet. A more complete understanding of cholera began when physician-scientists, versed in basic science and its

\footnotetext{
Address correspondence to: William B. Greenough III, The John R. Burton Pavilion, Johns Hopkins Bayview Care Center, 5505 Hopkins Bayview Circle, Baltimore, Maryland 21224, USA. Phone: (410) 550-0782 or (410) 550-0247; Fax: (410) 550-2513; E-mail:wgreeno2@jhmi.edu or wgreenou@hotmail.com.

Conflict of interest: The author is a shareholder in and scientific advisor to Cera Products Inc., Jessup, Maryland, USA, which manufactures the rice-based oral electrolyte solution CeraLyte.

Nonstandard abbreviations used: oral rehydration therapy (ORT); International Rice Research Institute (IRRI); Cholera Research Laboratory (CRL); International Centre for Diarrhoeal Disease Research, Bangladesh (ICDDR,B); International Centers for Medical Research and Training (ICMRT); oral rehydration solution (ORS).
}

technologies, undertook clinical studies in South and Southeast Asia where cholera was endemic. This "bringing science to where the diarrhea is" (1) dissipated the dogma of Rudolph Virchow - often considered the father of modern pathology - which insisted that Vibrio cholerae irreversibly damaged intestinal epithelium, causing the loss of protein-rich body fluids, just as one sees when the epithelium of other tissues is destroyed. This theory was based on poorly collected clinical specimens from patients in India suffering cholera-induced shock for prolonged periods with resulting ischemia and mucosal autolysis. Virchow's ideas took nearly a century to disprove (2). His method, which depended on sample collection by poorly informed and supervised workers in Calcutta, who then shipped them to his home laboratory in Europe, proved to be seriously flawed. From 1960 to 1970, research by clinician-scientists on site in Dhaka, Bangladesh (previously East Pakistan) and Calcutta, India demonstrated that the digestive system was not damaged during cholera infection and was rap- idly exchanging fluids and electrolytes with net secretion preeminent. The accurate measurement of the composition of intestinal secretions and the clear demonstration that net fluid and electrolyte absorption could be achieved in cholera patients when glucose was added to perfusing electrolyte solutions formed the foundation not only for highly effective intravenous rehydration but also for oral rehydration therapy (ORT). The beauty of ORT is that it does not require medical skills to administer and it is inexpensive. Both of these features make it accessible to nearly everyone, regardless of location or financial resources (3). Today, over 100 countries have programs to deliver this life-saving treatment, and ORT is used in over $50 \%$ of all cases of diarrhea. The development and global application of ORT has decreased the death rates from diarrheal diseases by more than half in the last 30 years.

\section{In the beginning}

It was the agricultural sciences that first broke ground in establishing facilities where scientists from many different countries could do research with advanced technologies on crops in their natural settings. In 1958, the International Rice Research Institute (IRRI) was established in Los Baños, Philippines. Dedicated to aiding farmers in developing countries in producing more food on limited land while using less labor and water and fewer chemical additives, this institute was the first step in what is now called "the Green Revolution" (4), which has allowed the rapid and increased production of specific foodstuffs in order to meet the needs of a rapidly expanding world population. The IRRI and its successors have taken science and advanced technologies to centers in remote areas and staffed them with top researchers, and through extension activities have put their laboratory findings into practice, first locally, then globally. This network of agricul- 


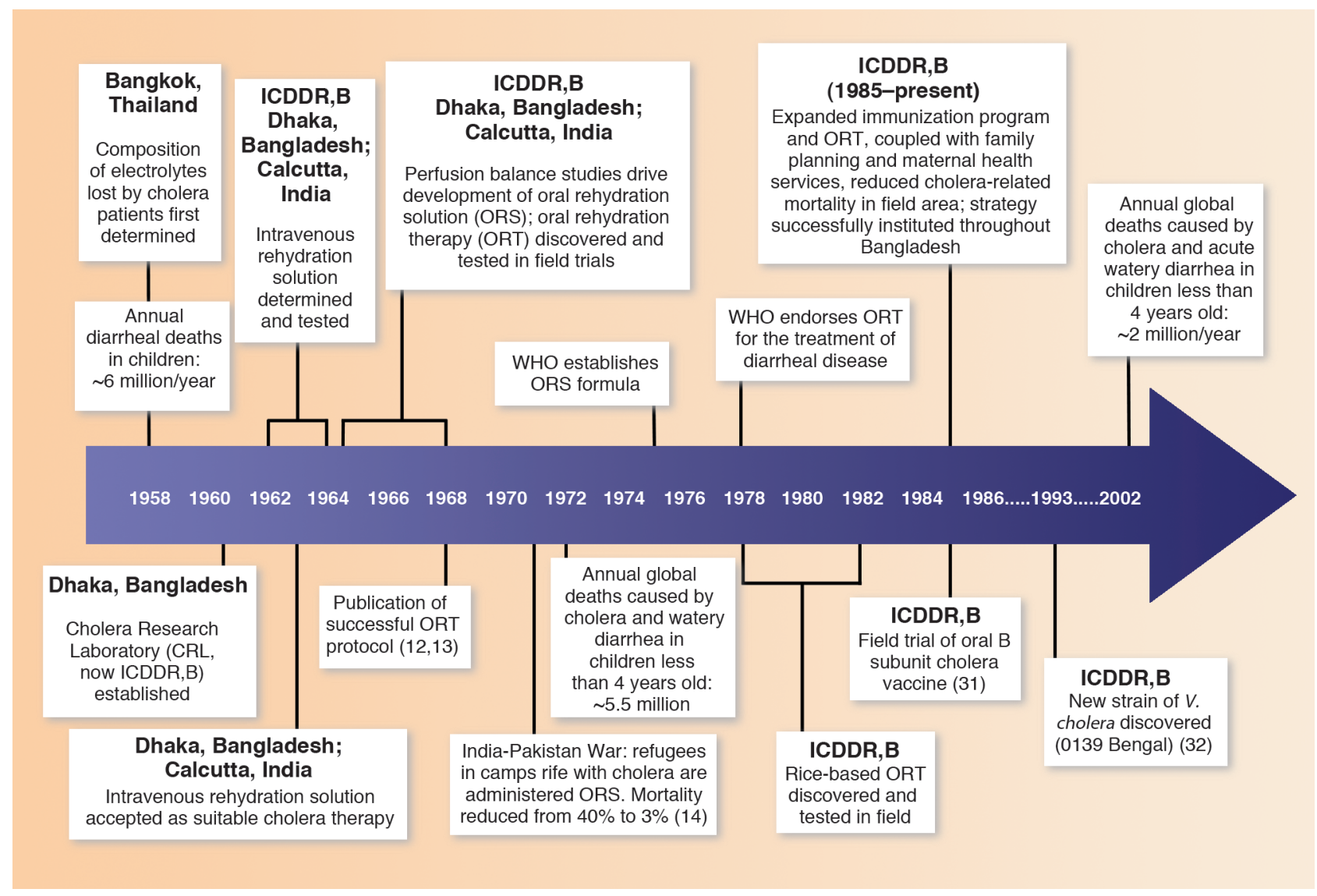

Figure 1

Chronological landmarks during the development of current cholera therapies, including important achievements of the ICDDR,B.

tural research centers has been coordinated and supported by the Consultative Group for Agricultural Research under the auspices of the World Bank.

The adaptation of the agricultural sciences model to basic health science practice in developing countries has been partially realized. In 1960, Fred Soper used the charter of the Institute of Nutrition of Central America and Panama as a model for establishing the Cholera Research Laboratory (CRL) in Dhaka, and in doing so became the first CRL Director. In 1978, the CRL became the International Centre for Diarrhoeal Disease Research, Bangladesh (ICDDR,B). Its charter was negotiated with the government of Bangladesh and was accepted by the United Nations Development Program at a meeting hosted by the WHO in Geneva in 1979. It incorporated features of the International Agricultural Research Centers, as well as features from previous international health research efforts in developing countries, which ensured that scientists from all countries (developed and developing) could be recruited to work without lengthy or obstructive visa processing and that supplies and technologies could be imported without duties or customs delays. The sovereignty of the host country was protected by the ex officio presence on the governing boards of trustees by positions designated by the host country, which included the Secretary of Health, the Secretary of the External Resources Department, and a third respected member from the local scientific and/or public health fields. Thus, the charter of the ICDDR,B is a conceptual blend of the charters of the agricultural and health sciences. In December 2003, the ICDDR,B celebrated its 25 th anniversary, marking its contributions to science and global health (Figure 1).

Many diseases have highly specific relationships with a particular geographic location and ecology. Under- standing interactions between humans and the agents that cause specific diseases requires sustained research at sites where disease is prevalent. Only years of sustained observation and hypothesis testing have clarified the mechanisms by which cholera is maintained in the surface waters of rural and urban areas of Bangladesh and how it causes seasonal epidemics in human populations. A precise model of the interaction of $V$. cholerae with phytoplankton could only have been determined at a location where cholera was endemic (5). In order to effectively study the epidemiology and pathophysiology of cholera in countries with limited or low resources, a stable institution in situ with excellent advanced laboratories and a dedicated staff of high-quality scientists and technicians was necessary. The rapid, efficient sharing of patient cultures and serum samples with collaborating laboratories throughout the world has been of critical importance. Such specimens were usually hand carried by the 
a

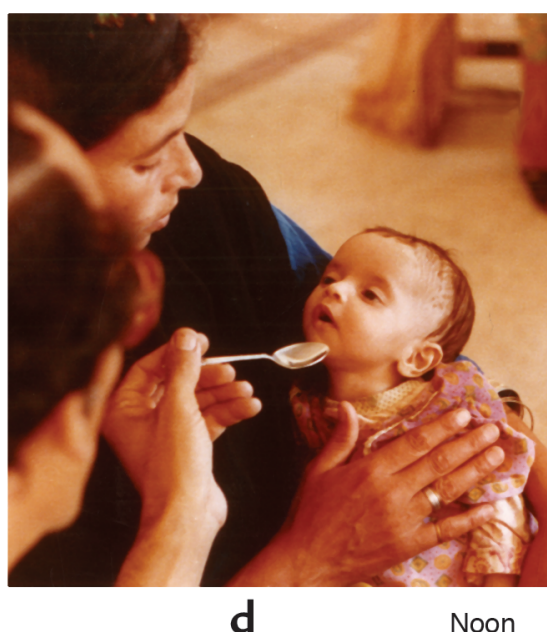

d

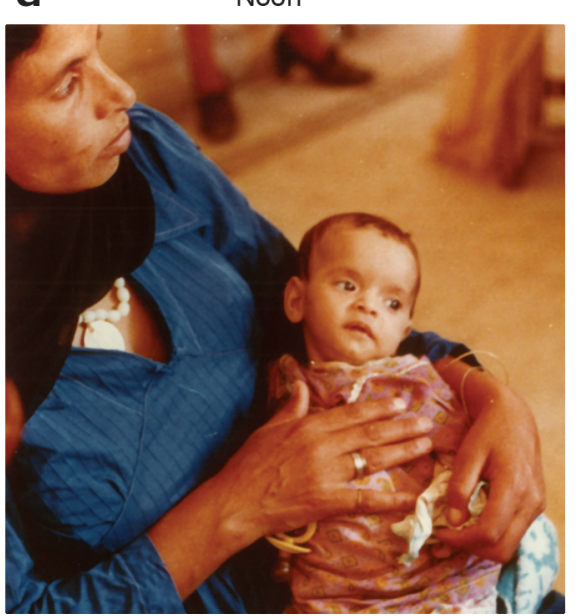

b

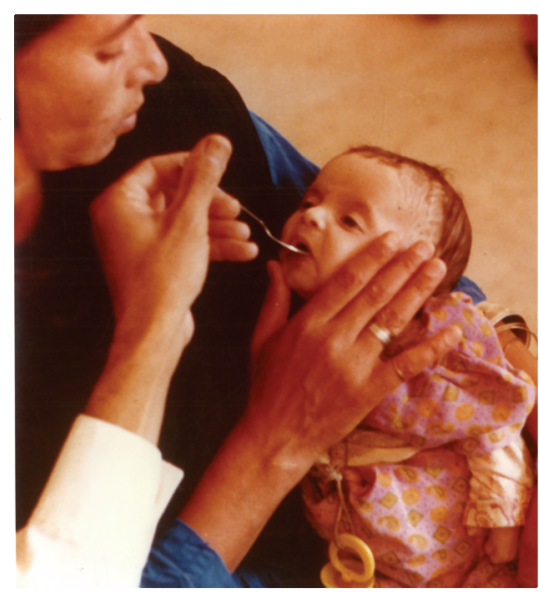

e
C

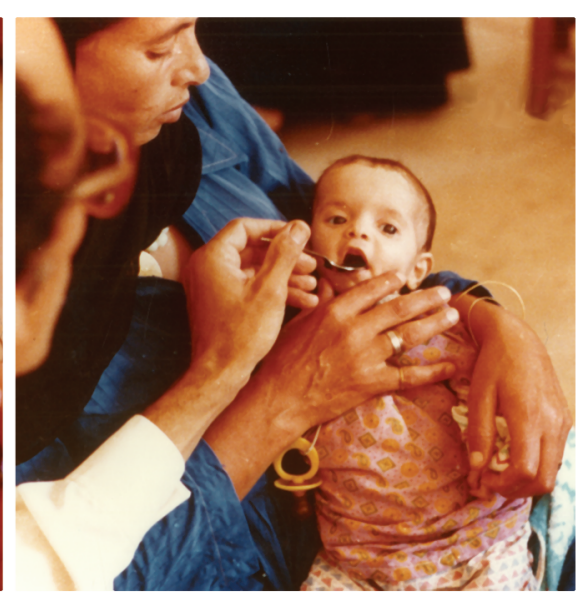

$1: 15 \mathrm{pm}$

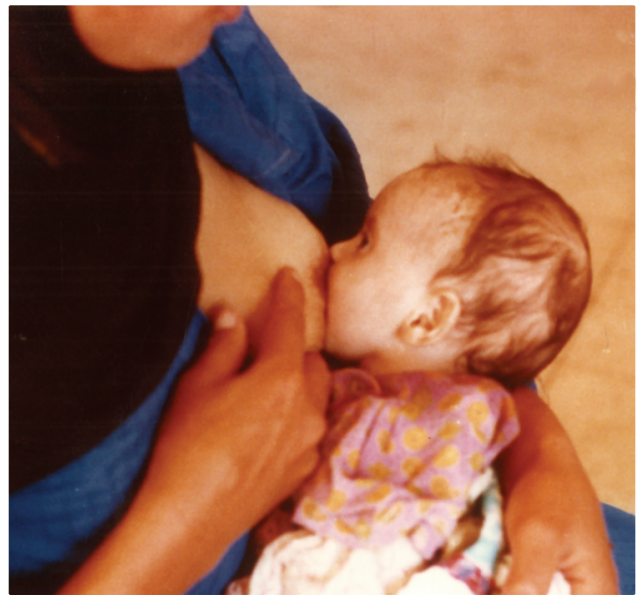

Figure 2

A three-month-old Egyptian boy in a rehydration treatment and training center is rescued with oral rehydration solution. By clinical estimate he had lost between five and ten percent of body weight in fluid. Normally in such centers the mother would give the fluid under a nurse's supervision, but in this instance a physician is gaining direct experience. (a and $\mathbf{b}$ ) Initially the infant must be coaxed to take the drink, which is given at an average rate of five cc (one teaspoon) a minute. (c) Within an hour, having absorbed needed electrolytes and water, he accepted the spoonfuls eagerly. (d) He lost interest at noon, once he had taken what he needed. Already the signs of dehydration - limpness, sunken eyes and flattening of the fontanelle - were gone. (e) Soon after, he was hungry for breast milk, which provided additional water and whose protein and carbohydrate nutrients promote movement of fluid from the intestine to the bloodstream, thus reducing the loss of diarrheal fluid. Figure kindly provided by Norbert Hirschhorn and reproduced with permission from Scientific American (33).

responsible investigators, historically the surest and safest means for rapid sharing of valuable specimens and accompanying documentation between laboratories (6).

\section{Intravenous rehydration therapy: a legacy of cholera}

Perceptive clinical observations by physicians caring for patients during the 1832 cholera epidemic in London led to the first recorded use of intravenous rehydration therapy (7). However, it was not until 1958, when the U.S. Naval Medical Research Unit 2 in Bangkok, Thailand recorded precise measurements of the volume and composition of stool samples from cholera patients, that a basis was established for an accurately constituted replacement solution (8). From 1962 to 1964 , supported by an NIHsponsored International Centers for Medical Research and Training (ICMRT) grant, Johns Hopkins University researchers at the Infectious Diseases Hospital of Calcutta and the Calcutta School of Tropical Medicine modified and simplified intravenous replacement methods, as did the CRL in Dhaka. The studies in Dhaka and Calcutta demonstrated that cholera patients, even those in deep shock, could be saved by the rapid and sustained infusion of appropriately constituted intravenous replacement solutions. Adequate intravenous rehydration of cholera patients in Dhaka and Calcutta reduced their mortality rate from approximately $30-40 \%$ to less than $0.5 \%$. By 1963 it was clear that any individual suffering from cholera who received timely, pyrogenfree, appropriately constituted intravenous solutions in sufficient quantity would survive. Clinician-scientists at the University of Baghdad, Iraq utilized the published reports of the 
intravenous rehydration therapy research performed in Dhaka and independently confirmed the efficacy of the therapy under epidemic conditions (9). However, intravenous fluid therapy is costly, requires specialized equipment, and must be administered by highly trained doctors and technicians. It remains inaccessible to individuals in resource-poor locales where cholera and other dehydrating diarrheas take the greatest toll. Physicians working in Dhaka and Calcutta, who had experienced mass cholera epidemics, quickly realized that an alternative way to replace the water and salt lost by cholera patients needed to be found if many more lives were to be saved.

\section{The advent of ORT}

Fortunately, investigators in both Dhaka and Calcutta were aware of reports of carrier-mediated sodiumglucose transport (10) and took this knowledge to the bedside of cholera patients between 1964 and 1967. Initial observations of electrical potential changes across intestinal epithelium (11) followed by perfusion balance studies showed that even during cholera, the most severe of the watery diarrheas, the right amount of glucose incorporated into an electrolyte replacement solution matching intestinal fluid losses could stimulate substantial absorption (12, 13). Thus, ORT was born. In 1971, during the India-Pakistan War, East Pakistan proclaimed its independence as the new state of Bangladesh, and nine million refugees poured into India. This led to a cholera epidemic in which $30-40 \%$ of the infected patients died. Investigators from the Johns Hopkins University ICMRT in Calcutta were able to apply, on a massive scale, what had been learned from clinical studies (14). The administration of ORT alone reduced mortality to $3 \%$ (Figure 2 ). If initial intravenous rehydration of patients in shock due to choleraengendered dehydration was also employed, less than $1 \%$ of infected individuals died. By the mid-1970s, a standard oral rehydration solution (ORS) was agreed upon (Table 1). In 1978, the Diarrheal Diseases Control Program instituted by the WHO employed ORT as the centerpiece of its global effort to reduce deaths due to dehydrating diarrheal illness. As of 2002 , it is estimated that three million lives are saved annually through the use of ORT. In 1978, a Lancet editorial titled "Water with sugar and salt" stated that "The discovery that sodium transport and glucose transport are coupled in the small intestine, so that glucose accelerates absorption of solute and water was potentially the most important medical advance this century" (15). Rarely has science so swiftly transmuted an arcane biophysical observation into a practical, lowcost treatment that continues to save millions of lives each year without the need for hospitals, trained staffs, or advanced technologies.

\section{Improved ORT: the role of digestible polymers}

Although extraordinarily successful, the glucose-based ORT solution has been improved. Not only are there other separate and distinct cotransport pathways in intestinal epithelium that include amino acids and peptides that remain functional during cholera and most other dehydrating diarrheas, but methods of delivering more substrate at low osmotic cost are also available. High osmolarity solutions in the gut lumen drain salts and water from the blood stream into the lumen and aggravate diarrhea and dehydration (16). Thus, simply increasing the amount of glucose or other small cotransport molecules in ORT solutions is counterproductive. This problem has been overcome by presenting glucose as a polymer (in the form of starch) at a low osmotic cost to the digestive system. Proteins can also be presented in this way and provide additional cotransporting amino acids and peptides at low osmolarity. Diges- tive enzymes degrade these food polymers into individual carrier molecules without causing an "osmotic penalty" (17). Rice-based ORT solutions hydrate diarrheal patients and shorten the duration of diarrhea, thereby reducing volume losses (18). By using an optimal amount of protein with a composition designed to provide maximum use of amino acid and peptide cotransport pathways, further benefits can be anticipated. Furthermore, consistent use of ORT to treat acute diarrheal episodes in infants favors a more rapid recovery from the illness and a swifter return to normal childhood growth curves $(19,20)$. Thus, the simple human act of giving someone a drink is transformed from a basic act of human kindness into a lifesaving therapy founded on basic concepts in physiological ion transport. Furthermore, this task can be performed by anyone - a family member, friend, neighbor, or even a health worker. Thus, ORT blends both the science and humanity of medicine in a way we always desire, but rarely achieve. However, this "drink" (ORT) must be properly constituted and given in sufficient quantities to offset salt and water losses - not "any old drink" will do.

Cholera research has increased basic knowledge as well as saving lives. In Calcutta, at a time when it was not believed that Gram negative enteric bacteria could produce potent exotoxins, S.N. De, working independently, showed that bacteria-free filtrates of $V$. cholera placed in ligated rabbit ileal loops produced fluid accumulation (21). He postulated correctly that $V$. cholerae produced a potent exotoxin. Few believed De, but he was right. His observations attracted a young American microbiologist, Richard Finkelstein, who went to Calcutta, worked in De's laboratory, and ultimately isolat-

\section{Table 1}

Glucose and rice-based oral rehydration solutions

\begin{tabular}{lccccc}
\hline & $\begin{array}{c}\mathrm{Na} \\
\mathrm{mM} / \mathrm{I}\end{array}$ & $\begin{array}{c}\mathrm{K} \\
\mathrm{mM} / \mathrm{I}\end{array}$ & $\begin{array}{c}\text { Base } \\
\mathrm{mM} / \mathrm{l}\end{array}$ & $\begin{array}{c}\text { Osmolarity } \\
\mathrm{mM} / \mathrm{l}\end{array}$ & $\begin{array}{c}\text { Carbohydrate } \\
\text { kcal/l }\end{array}$ \\
$\begin{array}{lcccc}\text { Glucose ORS } \\
\text { Rice ORS }\end{array}$ & 90 & 20 & 30 & 311 & 80 \\
(CeraLyte) $^{\mathrm{B}}$ & 90 & 20 & 30 & 265 & 165 \\
\hline
\end{tabular}

AWHO standard formula, Jianas Brothers Inc., Kansas City, Missouri, USA. ${ }^{B}$ Rice-based ORS, Cera Products Inc., Jessup, Maryland, USA. 
ed the toxin. He and others who purified this toxin shared preparations with many investigators as purification proceeded (22), thus facilitating the discovery of the mechanism of cholera toxin action $(23,24)$. The cholera toxin attaches to a GM1 ganglioside receptor on cell surfaces and stimulates adenylate cyclase (25). Fortunately, in nature the toxin binds only to gut epithelium and does not enter the bloodstream or cause systemic toxicity; thus replacement of fluid loss without additional therapeutic intervention is sufficient to treat the disease. Using purified cholera toxin, cellular biologists have learned the consequences of sustained increases of adenylate cyclase levels in many cell systems $(26,27)$. The genes controlling production of cholera toxin are now defined (28), and this knowledge is assisting in the design of more effective vaccines (29).

\section{What we have learned}

The legacy of cholera demonstrates how basic science - when brought to the bedside - can save lives, reduce costs, and prevent disease. It also illuminates aspects of intestinal transport as well as very basic cellular mechanisms. The promise of effective vaccines and environmental measures can now be realized. Advances in our understanding of the mechanism of action of cholera have revealed common pathways of secretory diarrhea, teaching us that ORT can be used to treat diarrhea regardless of etiology.

When young physician-scientists went to Dhaka and Calcutta in the 1960s through the visionary leadership of individuals including A.M. Harvey, Joseph Smadel, Abraham Benenson, Clifford Pease, Robert S. Gordon, Jr., and many others, and with the enthusiastic support of the NIH under the leadership of James Shannon, many skeptics believed that these young doctors should not "fritter away" time and money on a strange, exotic disease like cholera in an area remote from the US; after all, cholera hadn't been a problem for America in years. This perception turned out to have been spectacularly wrong. We have been greatly enriched by studies on cholera and the cholera toxin, and millions of lives have been saved. Beyond this, a stable institution - the ICDDR,B - has brought the best and most advanced science and technology to bear on the health problems of an area of the world with few resources in the health sector. It has also established a collegial cooperation among scientists from many countries of the world, both developed and developing, who have worked at the Centre. However, to achieve similar success in the treatment of other illnesses prevalent in underdeveloped countries in the 21 st century, visionary leaders such as those who fostered the work on cholera will be needed. They must raise the resources to put the best people and technology in the primary settings of high disease prevalence. Such efforts must be sustained over many years. The challenge in resource-poor settings where many of the most exigent health problems occur is that social turbulence is in some cases the rule, and institutions must be structured in order to allow work to proceed despite disruptions inherent in local, regional, and global turmoil. Agricultural science has certainly led the way in creating such stable, highquality international research centers in relevant ecological settings. The ICDDR,B has successfully established a model for international health research centers. It is perhaps time that a stable, well-staffed, well-equipped international center be established to longitudinally study the flux of retroviruses among humans and primates in the region where HIV arose. In our fight against this disease, short forays by scientists from rich countries to isolate and study samples have not sufficed to control this global epidemic.

Another recent impediment to the rapid breakthrough that characterized cholera research stems from our current fear of bioterrorism in the US. Legislation now designed to protect us impedes the rapid and free exchange of laboratory and clinical samples. U.S. microbiologist Thomas C. Butler, one of the leading authorities on plague, has recently been convicted and expects to be sentenced to several years in jail for his handling of plague specimens and grant support for research he performed in Tanzania in the devel- opment of antibiotics to treat clinical plague in humans (30). His case is a warning to researchers working with infectious agents that appear on the current "select list" maintained by the Department of Health and Human Services and the United States Department of Agriculture of specifically regulated pathogens and toxins that could be conceived as possible bioterrorism agents. It is likely that these events and restrictions will inhibit research in the US. The replication of results, so essential for rapid advances in science, is founded upon the unencumbered sharing of cultures, toxins, clinical specimens, and patient data by relevant laboratories and investigators throughout the world. That two teams - one in Dhaka and one in Calcutta were able to rapidly confirm each other's work by such collaborative means greatly accelerated progress in the treatment of cholera. The subsequent distribution of cholera toxin among many laboratories rapidly fostered our understanding of the mechanisms of diarrheal diseases as well as fundamental cellular processes.

The ICDDR,B has had directors from the US, Belgium, and Ethiopia. Not only have relationships with the Government of Bangladesh been cordial, but Bangladesh has contributed considerable financial and infrastructure support over the years. To an important extent, this stems from an early decision, still currently adhered to, that large numbers of patients would be cared for in all of the areas in which the Centre was carrying out research projects. In turn, the government has implemented in its national programs the most important findings from the Centre's research. Both local and foreign scientists have undertaken equal collaborations at the Centre, and many local scientists have since traveled to and maintained distinguished research careers at international institutions.

The ICDDR,B has continuously upgraded its scientific and technologic infrastructure so that the tools that it utilizes for disease diagnosis are at the forefront of modern technology. At present, under the leadership of David A. Sack, The ICDDR,B has become increasingly productive 
and currently receives support from a growing number of countries and agencies. In 2001, the ICDDR,B received the first Gates Award for Global Health from the Bill and Melinda Gates Foundation and continues to have strong support from the host country. It publishes a peerreviewed quarterly journal titled Journal of Health, Population, and Nutrition, which is listed in Index Medicus and is available online (www.icddrb.org/ jhpn). In 2002, scientists at the Centre published 80 original scientific articles, as well as 43 reviews or book chapters, which covered a range of topics from fundamental laboratory and clinical science to public health, population, and nutrition issues.

Those interested in global health will need to take courage in hand. It is in our own international, national, and personal interest to investigate the illnesses that afflict the poor in remote, underserved areas. Such efforts are not solely charitable. All individuals receive benefits from such research. Effective new preventive and curative measures will increasingly save lives in both resource-rich and -poor countries. The lessons learned from our experience with cholera need to be extended to the other most urgent health problems faced throughout the world. The ICDDR, $\mathrm{B}$ is a beacon, affirming the power of a multilateral collegial scientific effort in resource-limited settings.

\section{Acknowledgments}

Due to space limitations, many important individuals crucial to the success of intravenous and oral rehydration therapy for the treatment of cholera could not be mentioned by name. The author wishes to thank Norbert Hirschhorn for providing the images in Figure 2, David Sack, Director of the ICDDR,B, for helpful suggestions, and Terri Rigsby for assistance in preparing this manuscript.

1. Rohde, J.E., and Northrup, R.S. 1976. Taking science where the diarrhoea is. In Acute diarrhoea in childhood. CIBA Foundation Symposium 42. Elsevier. Amsterdam, The Netherlands. 339-358.

2. Carpenter, C.C.J. 1976. Treatment of cholera tradition and authority versus science, reason and humanity. Johns Hopkins Med. J. 139:153-162

3. Ruxin, J.N. 1994. Magic bullet: the history of oral rehydration therapy. Med. Hist. 38:363-397.

4. Evenson, R.E., and Gollin, D. 2003. Assessing the impact of the green revolution, 1960 to 2000 . Science. 300:758-762.

5. Colwell, R.R. 1996. Global climate and infectious disease: the cholera paradigm. Science 274:2025-2031.

6. Van Heyningen, W.E., and Seal, J.R. 1983. Cholera the American scientific experience, 1947-1980. Westview Press. Boulder, Colorado, USA. 300 pp.

7. O'Shaughnessy, W.B. 1831. Proposal of a new method of treating the blue epidemic cholera. Lancet. i:366.

8. Watten, R.H., Morgan, F.M., Songkhla, Y.N., Vanikiati, B., and Phillips, R.A. 1959. Water and electrolyte studies in cholera. J. Clin. Invest. 38:1879-1889.

9. Al-Awqati, Q.S., Mekkiya, M., and Thamer, M. 1969. Establishment of a cholera treatment unit under epidemic conditions in a developing country. Lancet. 1:252-253.

10. Schulz, S.G., Fuisz, R.E., and Curran, P.F. 1966 Amino acid and sugar transport in the rabbit ileum. J. Gen. Physiol. 49:849-866.

11. Sachar, D.B., Taylor, J.O., Saha, J.R., and Phillips, R.A. 1969. Intestinal transmucosal electric potential and its response to glucose in acute and convalescent cholera. Gastroenterology. 56:512-531.

12. Hirschhorn, N., et al.1968. Decrease in net stool output in cholera during intestinal perfusion with glucose-containing solutions. N. Eng. J. Med. 279:176-181.

13. Pierce, N.F., et al. 1968. Effect of intragastric glucose-electrolyte infusion upon water and electrolyte balance in Asiatic cholera. Gastroenterology. 55:333-343.

14. Mahalanabis, D., Chaudhuri, A.B., Bagchi, N.G. Bhattacharya, A.K., and Simpson, T.W. 1973. Oral fluid therapy of cholera among Bangladesh refugees. Johns Hopkins Med. J. 132:197-205.

15.1978. Water with sugar and salt. Lancet. 2:300-301.

16. Carpenter, C.C.J., Greenough, W.B., III, and Pierce, N.F. 1988. Oral rehydration therapy - the role of polymeric substrates. N. Eng. J. Med. 319:1346-1348.

17. Field, M. 2003. Intestinal ion transport and the pathophysiology of diarrhea. J. Clin. Invest. 111:931-943. doi:10.1172/JCI200318326.
18. Molla, A.M., Ahmed, S.M., and Greenough, W.B. III. 1985. Rice-based oral rehydration solution decreases the stool volume in acute diarrhoeas. Bull. World Health Org. 63:751-756.

19. Hirschhorn, N. 1980. The treatment of acute diarrhea in children: an historical and physiological perspective. Am. J. Clin. Nutr. 33:653-663.

20. Molla, A.M., Bari, A., and Greenough, W.B., III 1995. Rice-oral rehydration solution hastens recovery from dysentery. J. Diarrhoeal Dis. Res. 13:81.

21. De, S.N. 1959. Enterotoxicity of bacteria-free culture-filtrate of Vibrio cholerae. Nature. 183:1533-1534.

22. Finkelstein, R.A. 1992. Cholera enterotoxin (Choleragen): a historical perspective. In Cholera. D. Barua and W.B. Greenough III, editors. Plenum Medical. New York, New York, USA. 155- 187.

23. Field, M., Fromm, D., Al-Awqati, Q., and Greenough, W.B., III. 1972. Effect of cholera enterotoxin on ion transport across isolated ilea mucosa. J. Clin. Invest. 51:796-804.

24. Kimberg, D.V., Field, M., Johnson, J., Henderson, A., and Gershon, E. 1971. Stimulation of intestinal mucosal adenyl cyclase by cholera enterotoxin and prostaglandins. J. Clin. Invest. 50:1218-1230.

25. Van Heyningen, W.E., Carpenter, C.C.J., Pierce, N.F., and Greenough, W.B., III. 1971. Deactivation of cholera toxin by ganglioside. J. Infect. Dis. 124:415-418.

26. Fishman, P.H. 1990. Mechanism of action of cholera toxin. In ADP-ribosylation toxins and $G$ proteins. American Society of Microbiology. Washington, DC, USA. 127-137.

27. Bobak, D.A., Tsai, S.-C., Moss, J., and Vaughn, M 1990. Enhancement of cholera toxin ADP-ribosyltransferase activity by guanine nucleotidedependent ADP ribosylation factors. In ADP ribosylation toxins and $G$ proteins. J. Moss and M Vaughn, editors. American Society of Microbiology. Washington, DC, USA. 439-456.

28. Waldor, M.K., and Mekalanos, J.J. 1996. Lysogenic conversion by a filamentous phage encoding cholera toxin. Science. 272:1910-1914.

29. Lagos, R., et al. 1999. Palatability, reactogenicity and immunogenicity of engineered live ora cholera vaccine CVD $103 \mathrm{HgR}$ in children, infants and toddlers. Pediat. Infect. Dis. J. 18:624-630.

30. Miller, J.D. 2003. Caught in political crosshairs biodefense researchers face criminal charges and harassment. Scientist. 17:50,

31. Clemens, J.D., et al. 1990. Field trial of oral cholera vaccines in Bangladesh: results from a three year follow-up. Lancet. 335:270-273.

32. Waldor, M.K., and Mekalanos, J.J. 1994. Emergence of a new cholera pandemic: molecular analysis of virulence determinants in Vibrio cholerae 0139 and development of a live vaccine prototype. J. Infect. Dis. 170:278-283.

33. Hirschorn, N., and Greenough, W.B., III. 1991 Progress in oral rehydration therapy. Scientific American. 264:50-56. 